\title{
Protocol
}

\section{Labeling Neuronal Membrane Receptors with Quantum Dots}

\author{
Sabine Lévi, Maxime Dahan, and Antoine Triller
}

\section{INTRODUCTION}

This protocol describes a highly sensitive approach for tracking the motion of membrane molecules over extended time periods with single-molecule resolution. This technique uses nanometer-sized quantum dots (QDs) linked to the extracellular part of the proteins to be followed. Single-fluorophore epifluorescence imaging then reveals the membrane diffusion of the particle of interest. Two methods are presented for labeling neurons with the primary antibody of choice along with a secondary anti-Fab antibody that is either biotinylated or directly coupled to the desired QD. The behavior of QDlabeled molecules can then be followed within the cell using epifluorescence imaging.

\section{RELATED INFORMATION}

QD staining is easy, fast, and nontoxic and has low background fluorescence. QDs come in many colors and wide absorption spectra, yet have narrow emission spectra, facilitating multicolor detection. Moreover, QDs, which are $\sim 10-20 \mathrm{~nm}$ in diameter, intermediate between latex beads $(500 \mathrm{~nm})$ and conventional fluorophores $(\sim 1-4 \mathrm{~nm})$, can still access confined cellular domains such as the synaptic cleft. The photostability of QDs significantly extends the recording period duration (see the section, "Using QDs to Measure GlyR Diffusion," in the Discussion). Another key feature of QDs is their strong fluorescence. With an integration time of $75 \mathrm{msec}$, the spots are detected with a signal-to-noise ratio of $\sim 50$ (an order of magnitude more than that of traditional fluorophores). As a result, the lateral resolution with which individual QD spots can be localized reaches 5-10 nm, well below the $40 \mathrm{~nm}$ achieved with Cy3 (Dahan et al. 2003). Furthermore, QDs are brighter than conventional fluorescent molecules such as Cy3 and therefore require less excitation light. They can be excited with a mercury lamp instead of a laser beam, which is required for single $\mathrm{Cy} 3$ detection. The laser beam excites only a small region of the field compared to the mercury lamp, which excites the entire field equally and therefore permits imaging of more QDs per field. Consequently, multiple individual fluorescent spots can be observed simultaneously. In addition, the same QD probe can be used both at the optical and the electron microscope levels.

There are two main limitations to QD staining. First, QD blinking makes the analysis of long trajectories more complex and time-consuming, requiring sophisticated software. Second, particular attention should be given to the size of the QDs and the control of stoichiometries.

QD staining, as described in this article, has been used successfully in cultured neurons to follow the membrane diffusion of individual glycine receptors (Dahan et al. 2003; Charrier et al. 2006; Calamai et al. 2009); type A GABA receptors (Lévi et al. 2008; Bannai et al. 2009); AMPA receptors (Ehlers et al. 2007; Groc et al. 2007, 2008; Heine et al. 2008; Frischknecht et al. 2009); NMDA receptors (Groc et al. 2006; Michaluk et al. 2009); cannabinoid receptors (Mikasova et al. 2008); and lipid raft markers, glycophosphatidylinositol-anchored green fluorescent protein (GPI-GFP), and cholera toxin (Renner et al. 2009).

\section{MATERIALS}

RECIPES: Please see the end of this article for recipes for reagents marked with $<R>$.

It is essential that you consult the appropriate Material Safety Data Sheets and your institution's Environmental Health and Safety Office for proper handling of equipment and hazardous materials used in this protocol.

Adapted from Imaging in Neuroscience (ed. Helmchen and Konnerth).

CHSL Press, Cold Spring Harbor, NY, USA, 2011.

Cite as: Cold Spring Harb Protoc; 2011; doi:10.1101/pdb.prot5580

www.cshprotocols.org 


\section{Reagents}

Antibody, primary

Biotinylated secondary Fab antibody (Jackson ImmunoResearch Laboratories) (for labeling Method A) or QD F(ab')2 secondary lgG antibody (Invitrogen) (for labeling Method B)

Casein $(1 \times)$ (for labeling Method B)

FM4-64 (N-(3-triethylammoniumpropyl)-4-(6-(4-diethylamino)phenyl)hexatrienyl)pyridinium dibromide), $1 \mu \mathrm{M}$ in $40 \mathrm{mM} \mathrm{KCl}$

$<$ R $>$ MEM for QD imaging

Use this medium at $37^{\circ} \mathrm{C}$ for incubations, washes, and imaging.

Neurons for labeling

$<$ R $>$ QD streptavidin conjugate solution (for labeling Method A)

\section{Equipment}

Imaging setup

This procedure used an inverted microscope (Olympus, IX70 or 71) equipped with a $60 \times$ objective (numerical aperture $[N A]=1.45$; Olympus). QD-605 and FM 4-64 were detected using a mercury arc lamp (excitation filter 525DF45) and appropriate emission filters (595DF60 and 695AF55 from Omega Filters). For Cy3 excitation, to achieve single-dye detection, the sample was illuminated with a frequency-doubled YAG crystal laser at $532 \mathrm{~nm}\left(\sim 0.5 \mathrm{~kW} / \mathrm{cm}^{2}\right)$. For detection of single $Q D s$, the sample was illuminated with a mercury lamp. Real-time $Q D$ and $C y 3$ recordings were obtained at $13 \mathrm{~Hz}$ and $10 \mathrm{~Hz}$, respectively, using a charge-coupled device (CCD) camera (Micromax 512EBFT, Cascade + 128, Roper Scientific or ORCA II ER, Hamamatsu Photonics) with up to approximately 1000 consecutive frames under Metaview (Universal Imaging). Single-molecule trajectories were analyzed with custom-written routines (Bonneau et al. 2005) in MatLab (MathWorks). Similar algorithms are freely available (Jaqaman et al. 2008; Sergé et al. 2008).

Incubator preset to $37^{\circ} \mathrm{C}$

\section{METHOD}

1. Label neurons using one of the following two methods:

\section{Method A}

i. Incubate the neurons for $5 \mathrm{~min}$ with a high dilution $(\sim 1-10 \mu \mathrm{g} / \mathrm{mL})$ of primary antibody to label a small number of molecules.

ii. Wash the neurons three times without waiting, and then incubate them for $5 \mathrm{~min}$ in $\sim 10 \mu \mathrm{g} /$ $\mathrm{mL}$ biotinylated secondary Fab antibody.

iii. Incubate the neurons for $1 \mathrm{~min}$ in $\sim 0.5-2 \mathrm{nM}$ QD streptavidin conjugate solution.

\section{Method B}

iv. Mix $5 \mathrm{nM}$ primary antibody with $30 \mathrm{nM}$ QD F(ab')2 secondary $\lg \mathrm{G}$ antibody for 30 min at room temperature and then for an additional $15 \mathrm{~min}$ with $1 \times$ casein to block nonspecific binding.

v. Incubate the neurons for $10 \mathrm{~min}$ at $37^{\circ} \mathrm{C}$ with $0.06 \mathrm{nM}$ the precoupled QD-antibody.

vi. Rinse off excess antibody.

If sufficient primary antibody is available, the primary antibody can be bound directly to $Q D(\lg G / Q D$ ratio $=1: 1)$ with the QD antibody conjugation kit (Invitrogen) in a fast (few hours) and specific (coupling of thiols to maleimide groups) manner.

2. Label presynaptic boutons for $30 \mathrm{sec}$ with $1 \mu \mathrm{M} \mathrm{FM} 4-64$ in $40 \mathrm{mM} \mathrm{KCl}$. See Troubleshooting.

3. Wash the cells, mount the coverslip in a recording chamber, and image the cells for up to $30 \mathrm{~min}$ in the imaging medium.

In our experiments, we perform QD real-time imaging at $13 \mathrm{~Hz}$ for approximately 500 consecutive frames. Time-lapse recording is preferred in experiments intended to determine dwell times in compartments (e.g., synaptic) where the molecules might reside for long durations. We often capture a single image of the cell morphology with transmitted 
light and of the synaptic marker (FM4-64, Venus::gephyrin, or DsRed::Homer1c) with fluorescent light before the QD image sequence.

\section{TROUBLESHOOTING}

Problem: The diffusion coefficients of the molecule of interest may be changed by neuronal activity stimulation.

\section{[Step 2]}

Solution: Neuronal activity regulates the neurotransmitter receptor's lateral diffusion properties (Tardin et al. 2003; Groc et al. 2004; Ehlers et al. 2007; Lévi et al. 2008; Bannai et al. 2009). Therefore, the $\mathrm{KCl}$-induced FM4-64 synaptic vesicle loading may change the diffusion coefficients of the molecule of interest. As an alternative, one can use markers that do not require activity stimulation to be integrated into synaptic boutons (e.g., Mitotrackers; Invitrogen). Another option is to lipotransfect neurons with the main components of the inhibitory and excitatory postsynaptic differentiations, such as Gephyrin and Homer1c recombinant proteins tagged with GFP variants.

\section{DISCUSSION}

\section{Interpretation of Imaging Data}

After imaging, the trajectory is reconstructed from the image sequence of a single QD identified by the intermittency in its fluorescence emission. QDs are classified as synaptic upon colocalization with a synaptic marker, such as glycine receptor (GlyR; see below) (e.g., see Fig. 1). For each QD, we calculate the mean square displacement (MSD), diffusion coefficient (D), confinement area, transition between

A
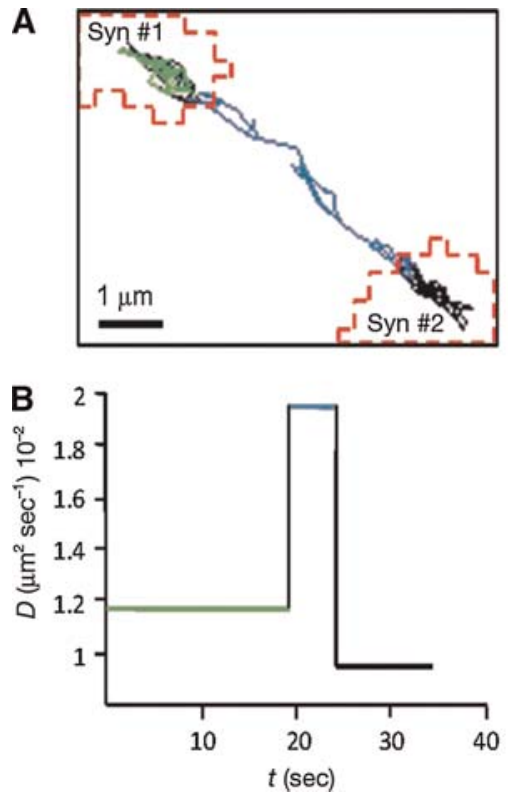

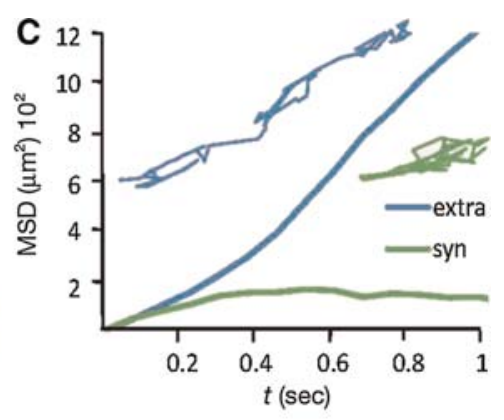

FIGURE 1. QD trajectory analysis. (A) Example of surface exploration by an itinerant GlyR-QD visualized on a reconstructed trajectory. QD trajectories in synaptic areas \#1 (Syn \#1, green) and \#2 (Syn \#2, black); FM4-64-stained synapses (red). Note the large surface area explored by the GlyR-QD outside (blue) the synaptic areas. Scale bar, $1 \mu \mathrm{m}$. (B) Average diffusion coefficients of the QD shown in A during its extrasynaptic (blue) and synaptic journey (green and blue). Note the changes in the QD diffusion coefficient when exiting synapse \#1 or entering synapse \#2, since there is one sudden increase and one drop. (C) Time-averaged MSD function of individual QD shown in A during its exploration of extrasynaptic (blue) and synaptic (green) loci during a recording sequence. The same QD displayed an extrasynaptic linear MSD curve and a synaptic negatively bent MSD curve, characteristic of random walk and confined movement, respectively. (For color figure, see doi: 10.1101/pdb.prot5580 online at www.cshprotocols.org.) 
compartments, and dwell time within a compartment. The MSD is determined from

$$
\operatorname{MSD}(n \tau)=\frac{1}{N-n} \sum_{i=1}^{N-n}\left[(x((i+n) \tau)-x(i \tau))^{2}+(y((i+n) \tau)-y(i \tau))^{2}\right],
$$

where $\tau$ is the frame acquisition time, $N$ is the total number of frames, and $n$ and $i$ are positive integers with $n$ determining the time increment. For simple two-dimensional (2D) Brownian mobility, the MSD as a function of time is linear with a slope of $4 D$. If the MSD as a function of time tends to a constant value $L$, the diffusion is confined in a domain of size $L$. The diffusion coefficient $(D)$ is determined by a fit on the first four points of the MSD as a function of time, with $\operatorname{MSD}(n \tau)=4 D n \tau+b$, where $b$ is a constant reflecting the spot localization accuracy. The area in which diffusion is confined can be estimated by fitting the MSD as a function of time to

$$
\operatorname{MSD}(n \tau)=\frac{L^{2}}{3}\left(1-\exp \left(-\frac{12 D n \tau}{L^{2}}\right)\right)+4 D_{\operatorname{mac}} n \tau,
$$

where $L^{2}$ is the confined area in which diffusion is restricted and $D_{\mathrm{mac}}$ is the diffusion coefficient on a long time scale.

\section{Using QDs to Measure GlyR Diffusion}

GlyR lateral diffusion was studied in cultured neurons using a single-particle tracking (SPT) approach (Dahan et al. 2003). Data obtained with Cy3 fluorophore coupled directly to primary antibody (Fig. 2A) were compared with data obtained using QD-605-streptavidin conjugates (Fig. 2B,C). Cy3and QD-tagged receptors were detected in extrasynaptic and synaptic regions. Individual Cy3 molecules were identified by their single-step bleaching. Cy3-GlyR could be tracked only for short durations ( $2.5 \mathrm{sec}$ in Fig. 2A, white arrow). In contrast, the photostability of QDs allowed QD-GlyR trajectories to be visualized (Fig. 2B,C) for unprecedented durations (20 min) (Fig. 2C; Movie 1).
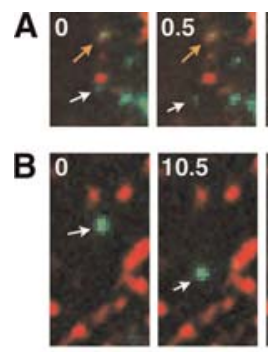

c
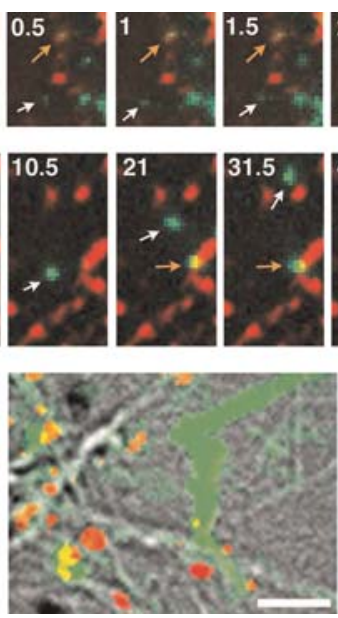
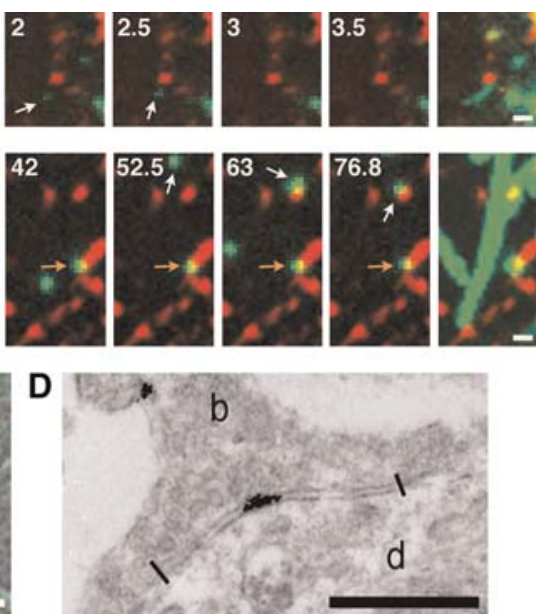

FIGURE 2. Comparison of lateral GlyR motion analyzed with Cy3 and QD probes. GlyRs were detected in cultured neurons with Cy3 (A) or QD-streptavidin (B,C). (Green) GlyR spots; (red) FM4-64-labeled synaptic boutons. $(A, B)$ Images were extracted from a sequence of 35 and 1024 images with an acquisition time of $100 \mathrm{msec}$ for Cy3 and 75 msec for QD. The time after the start of recording (in seconds) is indicated on each image. The last image is a maximum projection of the entire stack of images corresponding to the GlyR trajectory. (C) Projection of time-lapse recording (1 Hz, $20 \mathrm{~min})$ of QD-GlyR trajectory (green) overlaid with FM 4-64 staining (red) and bright-field image. (A-C) Cy3 and QD diffused rapidly in the extrasynaptic region (white arrows), whereas synaptic GlyRs were stable (orange arrows). Note the short membrane surface explored by Cy3-GlyR compared with QD-GlyR. Long QD imaging duration enabled the observation of a synaptic entry (white arrow in $B$ ). (D) EM detection of QD-GlyR within the synaptic cleft. (d) Dendrite; (b) synaptic bouton. The edges of the cleft are outlined. Scale bars, $1 \mu \mathrm{m}(A, B) ; 5 \mu \mathrm{m}(C) ; 500 \mathrm{~nm}(D)$. (For color figure, see doi: 10.1101/pdb.prot5580 online at www.cshprotocols.org.) 
MOVIE 1. Diffusion and stabilization of single QD-GlyRs (green). Time-lapse recording (1200 images at $1 \mathrm{~Hz}$; acquisition time, $75 \mathrm{msec}$ ). Synapses are labeled with FM4-64 (red). (To view movie, see doi: 10.1101 pdb.prot5580 online at www.cshprotocols.org.)

Single QDs were identified by the random intermittency of their fluorescence emission (Nirmal et al. 1996). For example, one QD (white arrow in Fig. 2B) temporarily disappeared after $31.5 \mathrm{sec}$ of recording. Long imaging duration enabled the observation of exchanges between extrasynaptic and synaptic domains, in which a GlyR alternated between free and confined diffusion states, respectively (white arrow in Fig. 2B). Silver-intensified and gold-toned QDs were detected using transmission electron microscopy (EM) with the same QD immunolabeling protocol (Fig. 2D). EM analysis provided evidence that QD-GlyR could access the core of the synapse (Fig. 2D). QD trajectories were reconstructed from recordings with custom "Sinema" software written in MatLab (Bonneau et al. 2005). Exploratory maps of trajectories indicated that individual QDs can exchange between extrasynaptic and synaptic compartments (e.g., blue and green trajectories, Fig. 1A). QDs diffused over broad areas of the extrasynaptic plasma membrane, whereas the QD exploratory map is reduced at synapses.

As exemplified (Fig. 1B) for the QD trajectory shown in Figure 1A, the average diffusion coefficient $(D)$ of the QD was lower within the synaptic area (Fig. 2, orange arrows). The plots of mean square displacement function (MSD) versus time were linear and negatively bent in the extrasynaptic and synaptic membrane, respectively (Fig. 1C), indicating a stronger confinement at synapses. This reflects local molecular interactions.

\section{REFERENCES}

Bannai H, Lévi S, Schweizer C, Inoue T, Launey T, Racine V, Sibarita JB, Mikoshiba K, Triller A. 2009. Activity-dependent tuning of inhibitory neurotransmission based on $G A B A_{A} R$ diffusion dynamics. Neuron 62: 670-682.

Bonneau S, Dahan M, Cohen LD. 2005. Single quantum dot tracking based on perceptual grouping using minimal paths in a spatiotemporal volume. IEEE Trans Image Process 14: 1384-1395.

Calamai M, Specht CG, Heller J, Alcor D, Machado P, Vannier C, Triller A. 2009. Gephyrin oligomerization controls GlyR mobility and synaptic clustering. / Neurosci 29: 7639-7648.

Charrier C, Ehrensperger MV, Dahan M, Lévi S, Triller A. 2006. Cytoskeleton regulation of glycine receptor number at synapses and diffusion in the plasma membrane. / Neurosci 26: 8502-8511.

Dahan M, Lévi S, Luccardini C, Rostaing P, Riveau B, Triller A. 2003. Diffusion dynamics of glycine receptors revealed by singlequantum dot tracking. Science 302: 442-445.

Ehlers MD, Heine M, Groc L, Lee MC, Choquet D. 2007. Diffusional trapping of GluR1 AMPA receptors by input-specific synaptic activity. Neuron 54: 447-460.

Frischknecht $\mathrm{R}$, Heine $\mathrm{M}$, Perrais $\mathrm{D}$, Seidenbecher $\mathrm{Cl}$, Choquet $\mathrm{D}$, Gundelfinger ED. 2009. Brain extracellular matrix affects AMPA receptor lateral mobility and short-term synaptic plasticity. Nat Neurosci 12: 897-904.

Groc L, Heine M, Cognet L, Brickley K, Stephenson FA, Lounis B, Choquet D. 2004. Differential activity-dependent regulation of the lateral mobilities of AMPA and NMDA receptors. Nat Neurosci 7: 695-696.
Groc L, Heine M, Cousins SL, Stephenson FA, Lounis B, Cognet L, Choquet D. 2006. NMDA receptor surface mobility depends on NR2A-2B subunits. Proc Natl Acad Sci 103: 18769-18774.

Groc L, Choquet D, Stephenson FA, Verrier D, Manzoni OJ, Chavis P. 2007. NMDA receptor surface trafficking and synaptic subunit composition are developmentally regulated by the extracellular matrix protein Reelin. / Neurosci 27: 10165-10175.

Groc L, Choquet D, Chaouloff F. 2008. The stress hormone corticosterone conditions AMPAR surface trafficking and synaptic potentiation. Nat Neurosci 11: 868-870.

Heine $M$, Groc L, Frischknecht R, Béïque JC, Lounis B, Rumbaugh $G$, Huganir RL, Cognet L, Choquet D. 2008. Surface mobility of postsynaptic AMPARs tunes synaptic transmission. Science 320: 201-205.

Jaqaman K, Loerke D, Mettlen M, Kuwata H, Grinstein S, Schmid SL, Danuser G. 2008. Robust single-particle tracking in live-cell timelapse sequences. Nat Methods 5: 695-702.

Lévi S, Schweizer C, Bannai H, Pascual O, Charrier C, Triller A. 2008. Homeostatic regulation of synaptic GlyR numbers driven by lateral diffusion. Neuron 59: 261-273.

Michaluk P, Mikasova L, Groc L, Frischknecht R, Choquet D, Kaczmarek L. 2009. Matrix metalloproteinase-9 controls NMDA receptor surface diffusion through integrin $\beta 1$ signaling. I Neurosci 29: 6007-6012.

Mikasova L, Groc L, Choquet D, Manzoni OJ. 2008. Altered surface trafficking of presynaptic cannabinoid type 1 receptor in and out synaptic terminals parallels receptor desensitization. Proc Natl Acad Sci 105: 18596-18601. 
Nirmal M, Dabbousi B, Bawendi MG, Macklin JJ, Trautman JK, Harris TD, Brus LE. 1996. Fluorescence intermittency in single cadmium selenide nanocrystals. Nature 383: 802-804.

Renner M, Choquet D, Triller A. 2009. Control of the postsynaptic membrane viscosity. J Neurosci 29: 2926-2937.
Sergé A, Bertaux N, Rigneault H, Marguet D. 2008. Dynamic multipletarget tracing to probe spatiotemporal cartography of cell membranes. Nat Methods 5: 687-694.

Tardin C, Cognet L, Bats C, Lounis B, Choquet D. 2003. Direct imaging of lateral movements of AMPA receptors inside synapses. EMBO J 22: $4656-4665$.

\section{RECIPES}

[NOTE: Recipes for reagents marked with the $<R>$ symbol not listed below can be found online at http:// www.cshprotocols.org/recipes.]

\section{MEM for QD imaging}

$4 \mathrm{mM} \mathrm{NaHCO}_{3}$

10 mM HEPES

$6 \mathrm{~g} / \mathrm{L}$ glucose

$2 \mathrm{mM}$ glutamine

$1 \mathrm{mM} \mathrm{Na}^{+}$pyruvate

1X B27 supplement (Invitrogen)

Prepare Eagle (1959) minimum essential medium without phenol red but containing the above reagents.

(Eagle H. 1959. Amino acid metabolism in mammalian cell cultures. Science 130: 432-437.)

\section{QD streptavidin conjugate solution}

0.5-2 nM QD 605 streptavidin conjugate (Invitrogen)

$50 \mathrm{mM}$ borate buffer ( $\mathrm{pH} 8-8.5)$

$215 \mathrm{mM}$ sucrose

The sucrose in the solution increases the osmolarity of the buffer to a physiological level (300 mosmol), whereas the borate buffer minimizes nonspecific QD labeling. 


\section{Labeling Neuronal Membrane Receptors with Quantum Dots}

Sabine Lévi, Maxime Dahan and Antoine Triller

Cold Spring Harb Protoc; doi: 10.1101/pdb.prot5580

\begin{tabular}{|c|c|}
\hline $\begin{array}{r}\text { Email Alerting } \\
\text { Service }\end{array}$ & Receive free email alerts when new articles cite this article - click here. \\
\hline $\begin{array}{l}\text { Subject } \\
\text { Categories }\end{array}$ & $\begin{array}{l}\text { Browse articles on similar topics from Cold Spring Harbor Protocols. } \\
\text { Antibodies, general (289 articles) } \\
\text { Cell Biology, general (1382 articles) } \\
\text { Cell Imaging (525 articles) } \\
\text { Fluorescence ( } 517 \text { articles) } \\
\text { Fluorescence, general (341 articles) } \\
\text { Image Analysis (124 articles) } \\
\text { Imaging for Neuroscience (342 articles) } \\
\text { Imaging/Microscopy, general (579 articles) } \\
\text { Immunofluorescence (51 articles) } \\
\text { Immunoimaging (41 articles) } \\
\text { Labeling for Imaging (339 articles) } \\
\text { Live Cell Imaging (274 articles) } \\
\text { Neuroscience, general (357 articles) } \\
\text { Video Imaging / Time Lapse Imaging (171 articles) } \\
\text { Visualization (524 articles) } \\
\text { Visualization of Gene Expression (127 articles) } \\
\text { Visualization, general (369 articles) }\end{array}$ \\
\hline
\end{tabular}

To subscribe to Cold Spring Harbor Protocols go to: http://cshprotocols.cshlp.org/subscriptions 